\title{
AVALIAÇÃO DA QUALIDADE DO LEITE CRU DURANTE ACOMPANHAMENTO TÉCNICO NAS PROPRIEDADES RURAIS DO MUNICÍPIO DE PEROBAL-PR
}

\author{
Marileide Ambrósio ${ }^{1}$ \\ Carolina Beraldo ${ }^{2}$ \\ Milene Ribeiro da Silva ${ }^{3}$ \\ Fábio Moritz ${ }^{4}$ \\ Cristiane Mengue Feniman Moritz ${ }^{5}$
}

\begin{abstract}
AMBRÓSIO, M.; BERALDO, C.; SILVA, M. R. da.; MORITZ, F.; MORITZ, C. M. F. Avaliação da qualidade do leite cru durante acompanhamento técnico nas propriedades rurais do município de Perobal-Pr. Arq. Ciênc. Vet. Zool. UNIPAR, Umuarama, v. 19, n. 4, p. 215-220, out./dez. 2016.
\end{abstract}

RESUMO: O objetivo deste trabalho foi avaliar a qualidade físico-química e microbiológica do leite cru, durante o acompanhamento técnico mensal sobre higienização e sanitização durante a ordenha em cinco propriedades rurais no município de Perobal/PR. As amostras de leite cru apresentaram-se em conformidade com a legislação vigente quanto aos parâmetros físico-químicos. Todas as amostras apresentaram ausência de Salmonella sp. Foram detectadas as contagens de aeróbios mesófilos e psicrotróficos dentro do limite máximo aceitável, com exceção do penúltimo mês de estudo para a contagem de mesófilos. Houve uma redução aparente nas contagens de coliformes $30^{\circ} \mathrm{C}$ nos dois últimos meses de estudo e na contagem de coliformes $45^{\circ} \mathrm{C}$ nas amostras de 3 produtores. Nos dois primeiros meses apenas dois produtores apresentaram amostras com contagens de estafilococos coagulase positiva, mas nos dois meses sequentes não houve a detecção de colônias nas amostras de todos os produtores. Entretanto, no último mês contagens entre 3,70 e $4,18 \log _{10} \mathrm{UFC} / \mathrm{mL}$ foram observadas em amostras de quatro produtores. Das 25 amostras, 22 (88\%) apresentaram as características de leite mastítico. As oscilações apresentadas entre os meses de estudo refletem um possível não comprometimento com as orientações técnicas recebidas, principalmente no último mês nas contagens de coliformes $45^{\circ} \mathrm{C}$ e estafilococos coagulase positiva.

PALAVRAS-CHAVE: Boas práticas. Contaminação. Ordenha.

\section{QUALITY ASSESSMENT OF RAW MILK DURING TECHNICAL MONITORING IN RURAL PROPERTIES IN THE CITY OF PEROBAL-PR}

\begin{abstract}
The purpose of this study was to assess the physical-chemical and microbiological quality of raw milk during monthly technical monitoring on five farms in Perobal/PR. Samples of raw milk were compliant to the current legislation regarding physical and chemical parameters. All samples showed no Salmonella sp., and mesophilic and psychrotrophic aerobic counts detected within the acceptable limit, except for the second last month of study for mesophilic counts. An apparent reduction was observed in the general and fecal coliform counts on the last two months of the technical support activity, specifically in samples from producers $\mathrm{P} 3$ and P4. On the first two months of the technical support activity, only two producers ( $\mathrm{P} 2$ and $\mathrm{P} 4$ ) had samples with positive coagulase staphylococci counts, but in the two subsequent months, no sequential detection of colonies were observed in the samples from all producers. However, in the last month, scores between 3.70 and $4.18 \log _{10} \mathrm{CFU} / \mathrm{mL}$ were observed in samples from four producers. From a total of 25 samples, $22(88 \%)$ presented characteristics of mastitic milk. The oscillations through the months of study reflect the possibility of no commitment with the technical guidance received, especially on the last month regarding the positive sign for fecal coliforms and coagulase staphylococci.
\end{abstract}

KEYWORDS: Contamination. Good practices. Milking.

\section{EVALUACIÓN DE LA CALIDAD DE LA LECHE CRUDA DURANTE ACOMPAÑAMIENTO TÉCNICO EN PROPIEDADES RURALES DEL MUNICIPIO DE PEROBAL-PR}

RESUMEN: El objetivo de este estudio há sido evaluar la calidad fisicoquímica y microbiológica de la leche cruda, durante el seguimiento técnico mensual de higiene y saneamiento durante el ordeño, en cinco granjas rurales del municipio de Perobal/PR. Las muestras de leche cruda se presentaron en conformidad con la legislación vigente en materia de los parámetros

DOI: https://doi.org/10.25110/arqvet.v19i4.2016.6099

${ }^{1}$ Tecnóloga de Alimentos, Especialista, Rodovia PR 323 Km 1,9 s/n, Zona Rural, CEP 87538000 - Perobal, PR, Brasil, ambrosio leide@yahoo.com.br ${ }^{2}$ Tecnóloga de Alimentos, Graduada, Av. Ângelo Moreira da Fonseca, 1800, Parque Danielle, CEP 97506-370 - Umuarama, PR, Brasil, carolinaberaldo@ hotmail.com

${ }^{3}$ Tecnóloga de Alimentos, Especialista, Av. Ângelo Moreira da Fonseca, 1800, Parque Danielle, CEP 97506-370 - Umuarama, PR, Brasil, ribeiro.milene@ gmail.com

${ }^{4}$ Médico Veterinário, Graduado, Av. Ângelo Moreira da Fonseca, 1800, Parque Danielle, CEP 97506-370 - Umuarama, PR, Brasil, fabiomoritz@yahoo. com.br

${ }^{5}$ Tecnóloga de Alimentos, Doutora, Av. Ângelo Moreira da Fonseca, 1800, Parque Danielle, CEP 97506-370 - Umuarama, PR, Brasil, crisfeniman@yahoo. com.br 
físicoquímicos. Todas las muestras mostraron ausencia de Salmonella sp. Se ha detectado en los recuentos de mesófilos aerobios y psicotrópicos dentro de los límites aceptables, con excepción del penúltimo mes de estudio para el recuento de mesófilos. Hubo una aparente reducción en el recuento de coliformes $30^{\circ} \mathrm{C}$ en los dos últimos meses de estudio, y en el recuento de coliformes $45^{\circ} \mathrm{C}$ en muestras de tres productores. En los dos primeros meses sólo dos productores presentaron muestras con recuento de estafilococos coagulasa positivos, pero en los dos meses siguientes no hubo detección de colonias en las muestras de todos los productores. Sin embargo, en el último mes en recuentos entre 3,70 y 4,18 $\log _{10} \mathrm{UFC} / \mathrm{mL}$ se observaron en muestras de cuatro produtores. De las 25 muestras, 22 (88\%) tenían las características de la leche mastítica. Las oscilaciones presentadas durante los meses de estudio reflejan um posible o ningún compromiso con las orientaciones técnicas recibidas, especialmente en el último mes con el recuento de coliformes $45^{\circ} \mathrm{C}$ y estafilococos coagulasa positivo.

PALABRAS CLAVE: Buenas prácticas. Contaminación. Ordeño.

\section{Introdução}

A bovinocultura é um dos principais destaques do agronegócio brasileiro, proporcionando grande lucratividade nas cadeias produtivas de carne e leite. Estima-se que o valor bruto da produção é de aproximadamente R $\$ 67$ bilhões, distribuídos em todos os estados brasileiros. Dessa forma, evidencia-se a importância econômica e social da bovinocultura no país (BRASIL, 2015a).

A produção de leite brasileira cresceu em média 4,5\% nos últimos anos. No entanto, a Embrapa Gado de Leite prevê que é pouco provável a manutenção da taxa de crescimento dos últimos anos. De acordo com projeções do Ministério da Agricultura, Pecuária e Abastecimento (MAPA), estima-se que a produção de leite crescerá a uma taxa anual entre $2,4 \%$ e $3,3 \%$ até 2025 , passando de uma produção de 37,2 bilhões de litros para valores entre 47,5 e 52,7 bilhões de litros (BRASIL, 2015b).

Apesar de o Brasil ser um dos maiores países produtores de leite, pesquisas científicas mostram a necessidade de melhorar a qualidade do leite para atender as exigências legais estabelecidas nesse país (BORGES, et al., 2013).

O leite quando formado em vacas sadias é completamente estéril, porém se contamina em seguida por bactérias que habitam os canais galactóforos. A secreção láctea pode iniciar a contaminação do leite antes de ser vertido para o meio externo. Após sua coleta, o leite fica exposto a contaminações por diferentes fontes e inúmeros tipos de micro-organismos (EVANGELISTA, 2003). A higiene da ordenha, o ambiente em que a vaca está alojada e os procedimentos de limpeza do equipamento e utensílios usados durante e após a ordenha são fatores que afetam diretamente a contaminação microbiana do leite cru (FAGUNDES et al., 2006).

A mastite é a principal afecção do gado leiteiro brasileiro, constituindo um fator limitante na produtividade das propriedades rurais. Além de afetar a saúde dos animais leiteiros, reduz a produção e causa alterações significativas na qualidade microbiológica do leite, tornando-se um dos fatores que não permitem que os produtores atinjam as metas determinadas pelo governo. Desse modo, o produtor é prejudicado por ter descontos no preço do leite, a indústria passa a ter um tempo de prateleira reduzido para o seu produto e o consumidor final também é prejudicado por não ter acesso a um produto de qualidade (LANGONI et al., 2011).

Todavia, a mastite tem um importante papel na qualidade microbiológica do leite, pois o processo infeccioso e inflamatório pode modificar a composição do leite, aumentando a contagem de células somáticas e até mesmo causar a morte de vaca, levando a grandes perdas econômicas (MELO et al., 2014).
O objetivo deste trabalho foi avaliar a qualidade físico-química e microbiológica do leite cru, durante o acompanhamento técnico mensal referente aos procedimentos profiláticos de higienização e sanitização na obtenção do leite em cinco propriedades rurais próximas ao município de Perobal/PR.

\section{Material e Métodos}

O estudo acompanhou cinco produtores de leite (P1, P2, P3, P4 e P5) vinculados a um laticínio situado no município de Perobal/PR.

Foram realizadas visitas mensais às propriedades entre os meses de fevereiro a junho de 2012, nas quais foram observados os requisitos dispostos na Instrução Normativa 62 de 29 de dezembro de 2011 do MAPA (BRASIL, 2011). Para as não conformidades, os produtores foram alertados para a adequação e foram orientados quanto aos procedimentos profiláticos de higienização durante a obtenção do leite.

Durante as visitas também foram coletadas duas amostras de leite de cada produtor, sendo que uma foi enviada ao laticínio para a realização das análises físico-químicas recomendadas para o controle diário de qualidade do leite cru refrigerado, entregue na plataforma de recepção da unidade processadora, de acordo com os métodos descritos na Instrução Normativa n. 68 de 12 de dezembro de 2006 - MAPA (BRASIL, 2006) e pelo Instituto Adolfo Lutz (2005). As análises realizadas foram: temperatura, teste do álcool/alizarol, acidez titulável, índice crioscópico, densidade relativa à $15^{\circ} \mathrm{C}$, teor de gordura e de proteína, porcentagem de extrato seco total e desengordurado, teste de mastite (California Mastitis Test-CMT) e pesquisa de antibióticos, de neutralizantes de acidez (bicarbonato de sódio e substâncias alcalinas), de conservantes $\left(\mathrm{H}_{2} \mathrm{O}_{2}\right)$, de reconstituintes de densidade (amido, cloretos, sacarose e amido), de sangue e de pus.

A outra amostra de leite foi enviada ao Laboratório de Microbiologia da Universidade Estadual de Maringá, Campus de Umuarama, Departamento de Tecnologia para o acompanhamento microbiológico.

A IN 62 - MAPA (BRASIL, 2011) preconiza apenas a contagem padrão em placas como requisito microbiológico a ser avaliado para a qualidade do leite cru refrigerado. Entretanto, por ser o leite um alimento de alto valor nutritivo e propício à contaminação por diversos micro-organismos patogênicos foram realizadas análises microbiológicas adicionais para as amostras de leite recebidas de cada produtor na unidade processadora, nos mesmos períodos de visitas às propriedades. As análises realizadas foram a contagem padrão em placas para aeróbios mesófilos e aeróbios psicrotróficos, coliformes $30^{\circ} \mathrm{C}$ (coliformes totais), coliformes $45^{\circ} \mathrm{C}$ 
(coliformes fecais), estafilococos coagulase positiva e Salmonella spp. (DOWNES, 2001).

Os resultados das análises de contagem padrão em placas para aeróbios mesófilos e aeróbios psicrotróficos, coliformes $30^{\circ} \mathrm{C}$, coliformes $45^{\circ} \mathrm{C}$ e estafilococos coagulase positiva foram comparadas por meio de análise de variância (ANOVA), considerando cada mês como um tratamento para cada produtor. Estabeleceu-se a utilização do teste de Tukey para comparação das médias, quando pertinente. O programa estatístico utilizado foi o Bioestat 5.0 (AYRES et al., 2007).

\section{Resultados e Discussão}

O Regulamento Técnico de Identidade e Qualidade de Leite Cru Refrigerado disposto na IN 62 - MAPA (BRASIL, 2011) prevê os requisitos para o leite cru refrigerado, que deve ter o aspecto de líquido branco opalescente homogêneo, com sabor e odor característicos e isento de sabores e odores estranhos, além da ausência de neutralizantes de acidez e reconstituintes de densidade. Os requisitos físicos e químicos devem atender ao teor original de gordura mínimo de $3,0 \mathrm{~g} / 100 \mathrm{~g}$ ), densidade relativa a $15^{\circ} \mathrm{C}$ de 1,028 a $1,034 \mathrm{~g} /$ $\mathrm{mL}$, acidez titulável de 0,14 a $0,18 \mathrm{~g}$ de ácido lático/100 mL, extrato seco desengordurado mínimo de $8,4 \mathrm{~g} / 100 \mathrm{~g}$, índice crioscópico de $-0,530^{\circ} \mathrm{H}$ a $-0,550^{\circ} \mathrm{H}$ e mínimo de $2,9 \mathrm{~g} / 100 \mathrm{~g}$ de proteínas.

Todos os produtores nos cinco períodos de análise apresentaram amostras de leite em conformidade com a legislação vigente quanto aos parâmetros físico-químicos, além de teste negativo para álcool/alizarol e ausência de antibióticos, de neutralizantes de acidez (bicarbonato de sódio e substâncias alcalinas), de conservantes $\left(\mathrm{H}_{2} \mathrm{O}_{2}\right)$, de reconstituintes de densidade (amido, cloretos, sacarose e amido), de sangue e de pus.

A IN 62 - MAPA (BRASIL, 2011) também preconiza o monitoramento da qualidade microbiológica do leite cru por meio da análise de contagem padrão em placas, a ser realizada mensalmente, com média geométrica sobre período de três meses.

Visando a ordenha higiênica do leite, medidas corretivas foram instruídas aos produtores, sendo então consideradas como investimentos de baixo custo, tais como procedimentos profiláticos de higienização de utensílios, equipamentos e operadores/ordenhadores, além da limpeza e desinfecção do úbere dos animais, realizando o pré-dipping (imersão da superfície tetos do animal em solução sanificante por 20 a 30 segundos, seguida de secagem com papel toalha descartável) e pós-dipping (imersão da superfície tetos do animal em solução sanificante), todos os procedimentos em conformidade com a IN 62 - MAPA (BRASIL, 2011).

Os resultados da contagem padrão em placas para aeróbios mesófilos e aeróbios psicrotróficos são apresentados na Figura 1. Na análise de aeróbios psicrotróficos foi considerado o valor mínimo detectável para a análise estatística nos casos em que não houve crescimento de colônias (2 $\log _{10}$ $\mathrm{UFC} / \mathrm{mL}$ ).
Figura 1: $\log _{10}(\mathrm{UFC} / \mathrm{mL})$ das contagens padrão em placas de aeróbios mesófilos e aeróbios psicrotróficos obtido de amostras de leite cru refrigerado durante os meses de fevereiro a junho de 2012 em cinco propriedades rurais localizadas no município de Perobal/PR.

* - Limite mínimo detectável pela técnica de semeadura em superfície.

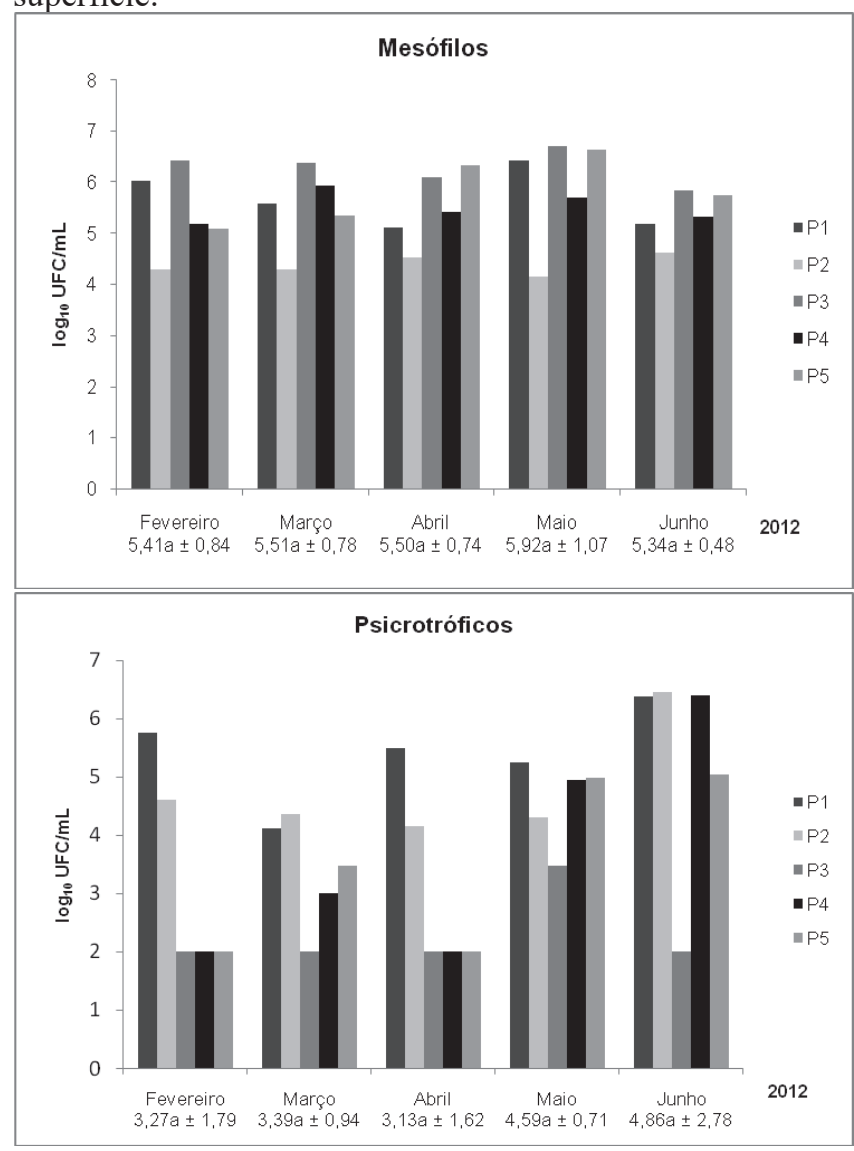

Foram observadas oscilações nas contagens de aeróbios mesófilos e aeróbios psicrotróficos, sem diferença estatística significativa a 5\%, entre os meses durante o acompanhamento técnico. Durante o estudo, as médias mensais da contagem de aeróbios mesófilos atenderam ao limite máximo aceitável naquele momento, com exceção do mês de maio. Até 31/12/2011 a IN 62 - MAPA (BRASIL, 2011) estipulava até $7,5 \times 10^{5} \mathrm{UFC} / \mathrm{mL}$, equivalente a $5,87 \log _{10} \mathrm{UFC} / \mathrm{mL}$. Atualmente, o limite máximo aceitável é de $10^{5} \mathrm{UFC} / \mathrm{mL}$ (5 $\left.\log _{10} \mathrm{UFC} / \mathrm{mL}\right)$.

Além da contagem padrão em placas foi realizada a contagem de coliformes, para avaliar a qualidade dos processos de higienização e sanitização da ordenha. Os resultados para coliformes $30^{\circ} \mathrm{C}$ e coliformes $45^{\circ} \mathrm{C}$ estão demonstrados na Figura 2. 
Figura 2: $\log _{10}(\mathrm{NMP} / \mathrm{mL})$ das contagens de coliformes $30^{\circ} \mathrm{C}$ e coliformes $45^{\circ} \mathrm{C}$ obtido de amostras de leite cru refrigerado durante os meses de fevereiro a junho de $2012 \mathrm{em}$ cinco propriedades rurais localizadas no município de Pero$\mathrm{bal} / \mathrm{PR}$.
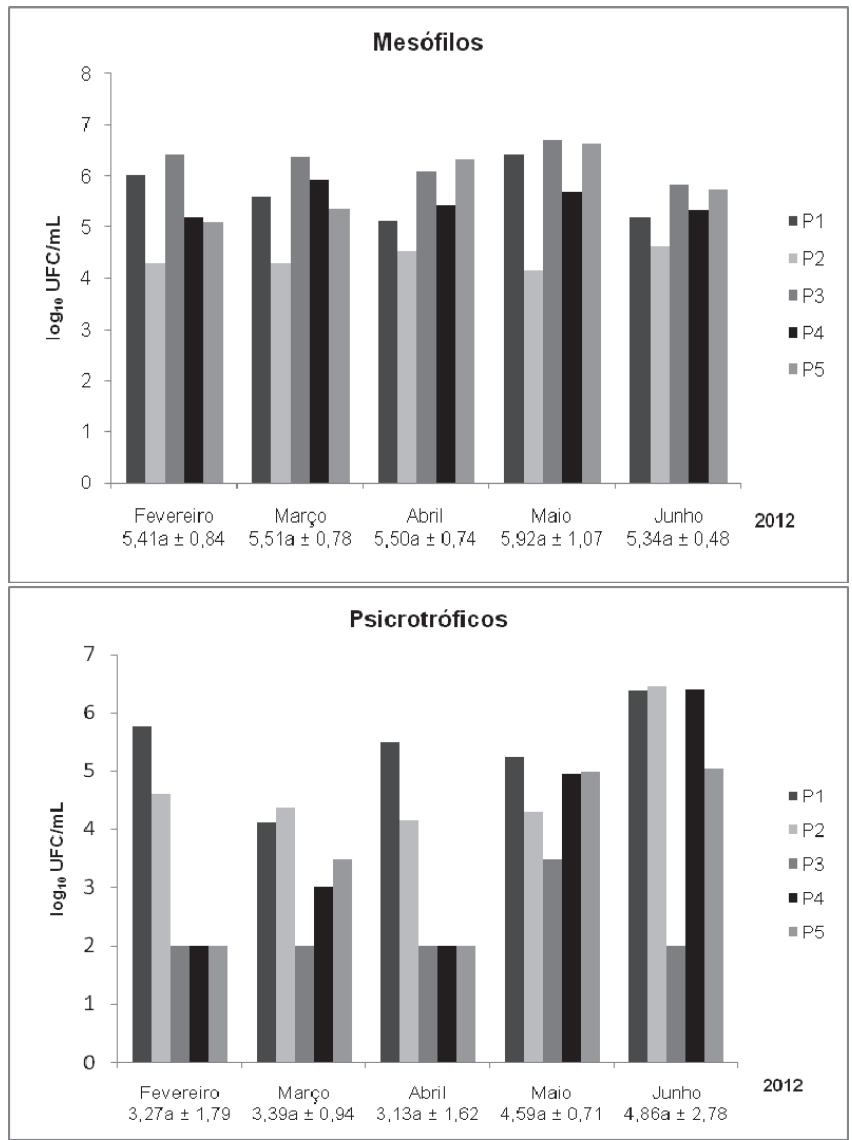

Apesar de não ter sido obtida diferença significativa a $5 \%$ entre as médias mensais de coliformes $30^{\circ} \mathrm{C}$ e coliformes $45^{\circ} \mathrm{C}$, é possível observar uma queda aparente nessas contagens dos dois últimos meses de acompanhamento técnico, como nos casos dos produtores P3 e P4. Como os coliformes $45^{\circ} \mathrm{C}$ são micro-organismos indicadores da presença de enteropatógenos, apesar das contagens elevadas desses, não foi detectada a presença de Salmonella spp. em nenhuma amostra de leite cru durante o estudo.

No entanto, as oscilações apresentadas entre os meses refletem um possível não comprometimento com as orientações técnicas recebidas, principalmente no último mês nas contagens de coliformes $45^{\circ} \mathrm{C}$ para os outros produtores. Essa situação também foi claramente observada para a contagem de estafilococos coagulase positiva (Figura 3).
Figura 3: $\log _{10}(\mathrm{NMP} / \mathrm{mL})$ da contagem estafilococos coagulase positiva obtido de amostras de leite cru refrigerado durante os meses de fevereiro a junho de 2012 em cinco propriedades rurais localizadas no município de Perobal/PR. * - Limite mínimo detectável pela técnica de semeadura em superfície.

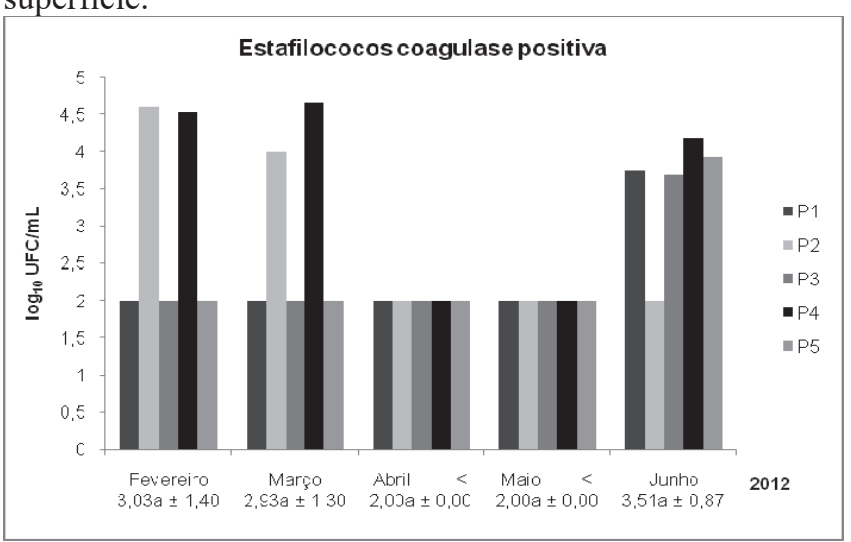

Da mesma forma que na contagem de aeróbios psicrotróficos, foi considerado o valor mínimo detectável para a análise estatística nos casos em que não houve crescimento de colônias (2 $\log _{10} \mathrm{UFC} / \mathrm{mL}$ ) de estafilococos coagulase positiva.

Não houve diferença estatística significativa a 5\% entres os meses em estudo para estafilococos coagulase positiva. Nos dois primeiros meses de acompanhamento técnico, apenas dois produtores ( $\mathrm{P} 2$ e $\mathrm{P} 4)$ apresentaram contagens detectáveis (4,61 e 4,53 $\log _{10} \mathrm{UFC} / \mathrm{mL}$, respectivamente) e nos meses de abril e maio não houve a detecção de colônias para todas as amostras. Entretanto, no último mês apenas o produtor P2 manteve a contagem menor de $2 \log _{10} \mathrm{UFC} / \mathrm{mL}$, sendo que os demais produtores apresentaram contagens entre 3,70 e 4,18 $\log _{10} \mathrm{UFC} / \mathrm{mL}$.

A espécie Staphylococcus aureus é um dos agentes mais importantes causadores de mastite clínica, subclínica, recorrente e crônica em bovinos leiteiros (MELCHIOR et al., 2006).

Neste estudo não foi possível realizar a contagem de células somáticas, porém foi realizado o teste CMT para a identificação qualitativa de leite mastítico. Das 25 amostras obtidas de cinco produtores de leite acompanhados durante os cinco meses de estudo, 22 amostras (88\%) apresentaram as características de leite mastítico (formação de coágulos, maior viscosidade e coloração avermelhada). Langoni (2013) ressalta a importância de detectar e definir os casos de mastite, que se caracteriza por alterações nas características do leite (como cor, produção de grumos, pus e sangue) nos casos de clínicos e nos casos subclínicos o leite apresenta-se aparentemente normal, mas é possível serem diagnosticados pela contagem de células somáticas ou visualmente pelo teste CMT, que mostra alterações na viscosidade do leite quando esse reage com o reagente púrpura de bromocresol.

Borges et al. (2013) caracterizaram a produção de leite nas mesorregiões Central Mineira e do Oeste de Minas do estado de Mina Gerais (responsável por 30\% da produção nacional) quanto à contagem de células somáticas, à contagem bacteriana total e à composição do leite, em diferentes faixas de volume de produção. Esses autores constataram que a contagem bacteriana total foi o fator de qualidade mais 
crítico do leite, sendo que a média ultrapassou o limite de $3 \times 10^{5} \mathrm{UFC} / \mathrm{mL}$ preconizado pela IN 62 do MAPA para o período em que foi publicado o estudo.

E um estudo realizado nas regiões catarinenses do Meio-Oeste e Alto Vale do Itajaí, Winck e Thaler Neto (2012) diagnosticaram que o leite era uma das duas principais atividades econômicas em $88 \%$ das propriedades, sendo realizada a ordenha manual em $33,7 \%$ e em estábulo convencional (94\%). Em 56,6\% das propriedades o resfriamento do leite era feito por imersão em água gelada, mas era crescente a utilização de resfriador por expansão direta por estar relacionada com a preocupação dos produtores em melhorar o resfriamento do leite de forma homogênea, além de terem o incentivo das indústrias ao pagarem um adicional para as propriedades que possuíam este equipamento. Entretanto, na pesquisa realizada ficou perceptível a reduzida preocupação na melhoria da higiene do leite e na saúde da glândula mamária dos animais.

Krewer et al. (2013) identificaram os fatores de riscos para a mastite, em sistema de criação extensivo, como sendo: a não realização de suplementação alimentar, o processo de secagem dos tetos, a não realização de desinfecção dos tetos antes e após a ordenha e os hábitos higiênicos inadequados dos ordenhadores. As boas práticas para a obtenção de uma ordenha higiênica devem ser estabelecidas, com o intuito de prevenir novos casos de mastite nos rebanhos.

Melo et al. (2014) isolaram linhagens de $S$. aureus do ambiente de ordenha (borrachas de ordenhadeiras e mangueiras condutoras de leite). Ao testarem o efeito do hipoclorito de sódio contra essas linhagens, constataram que o contato superficial dos materiais com o hipoclorito de sódio a $150 \mathrm{ppm}$ por dez minutos impediu o desenvolvimento da população bacteriana e produção de biofilme. Desse modo, a aplicação correta do protocolo de saneamento nas unidades de obtenção e processamento do leite reduz significativamente a presença de $S$. aureus, consequentemente, contribuindo para a profilaxia da mastite e reduzindo a contaminação do leite.

Ramalho et al. (2012) avaliaram a eficácia in vitro de desinfetantes contra isolados de $S$. aureus do leite de vacas com mastite subclínica. Com exposição de 60 minutos, a maior atividade desinfetante in vitro foi verificada para os agentes clorexidine $2,0 \%$ e cloro $2,5 \%$. Em função das variações do perfil de sensibilidade observadas no estudo, os autores ressaltaram a necessidade de avaliação regular da eficiência dos desinfetantes usados nas propriedades, com o intuito de garantir o controle da mastite no rebanho.

No entanto, o monitoramento contínuo do nível de infecção no rebanho é outro aspecto importante do controle de mastite bovina. A eliminação de infecções existentes tem mostrado ser de difícil aplicação em regimes de tratamento padrão, a menos que extensa seleção e alojamento adequado das vacas contaminadas sejam realizados. Assim, é essencial que o produtor seja capaz de identificar as vacas infectadas e separá-las de forma confiável do restante do rebanho (GODDEN, et al., 2002).

No momento da ordenha é importante o exame físico para identificar o processo inflamatório na glândula mamária, além da realização do teste de mastite nos primeiros jatos de leite de cada quarto mamário por meio do teste de CMT. Entretanto, Krewer et al. (2013) encontraram resulta- dos positivos no teste de CMT e na cultura microbiológica do leite em apenas $41,5 \%$ e $42 \%$, respectivamente, dos quartos mamários diagnosticados com mastite clínica. E em 12,6\% das amostras que foram negativas no teste de CMT, foram positivas na cultura microbiológica. Esses dados evidenciam que mesmo utilizando os métodos de triagem de mastite, como o teste de CMT, pode haver a incidência de animais contaminados por agentes causadores de mastite. De acordo com Riekerink et al. (2008), 15 a 40\% das amostras de leite podem ser negativas no teste de CMT, mesmo estando associadas aos quartos com alterações clínicas, em função de fatores como a baixa concentração ou eliminação dos agentes patogênicos no leite, localização intracelular dos patógenos, eliminação espontânea da infecção ou casos de mastite não infecciosa.

Normalmente, os casos de mastite causados por estafilococos coagulase negativos apresentam-se menos severos e persistentes, sendo considerados como mastite subclínica. Esses casos não apresentam dificuldades para uma eficiente terapêutica, com altas taxas de cura após o tratamento com antimicrobianos. Entretanto, é difícil determinar se as espécies comportam-se como patógenos contagiosos ou apenas ambientais, o que ressalta a importância das medidas de higiene, sanitização e desinfecção durante a ordenha para aperfeiçoar a qualidade do leite cru (PYÖRÄLÄ; TAPONEN, 2009).

\section{Conclusão}

Durante todos os meses de estudo, as amostras de leite apresentaram-se em conformidade com a legislação vigente quanto aos parâmetros físicos e químicos, além de teste negativo para álcool/alizarol e ausência de antibióticos, de neutralizantes de acidez, de conservantes, de reconstituintes de densidade, de sangue e de pus.

Apesar de não ter sido detectada diferença estatística significativa a 5\% entre as médias de contagem bacteriana (aeróbios mesófilos, aeróbios psicrotróficos, coliformes a $30^{\circ} \mathrm{C}$, coliformes a $45^{\circ} \mathrm{C}$ e estafilococos coagulase positiva) durante os meses de acompanhamento técnico sobre higienização e sanitização nas propriedades rurais, houve uma redução aparente na contagem de coliformes $30^{\circ} \mathrm{C}$ durante o estudo, demonstrando que o acompanhamento educativo dos produtores pode contribuir para melhorar a qualidade do leite cru. Entretanto, as oscilações apresentadas entre os meses refletem um possível não comprometimento com as orientações técnicas recebidas, principalmente no último mês, já que as contagens de coliformes $45^{\circ} \mathrm{C}$ e estafilococos coagulase positiva aumentaram. Houve detecção de leite mastítico em $88 \%$ das amostras, o que ressalta a importância da implantação e acompanhamento das medidas de higiene, sanitização e desinfecção durante a ordenha.

\section{Referências}

AYRES, M. et al. BioEstat: Aplicações estatísticas nas áreas das ciências biomédicas. Belém: Universidade Federal do Pará, 2007, 364p.

BRASIL. Ministério da Agricultura, Pecuária e Abastecimento. Instrução Normativa n. 68 de 12 de 
dezembro de 2006. Dispões sobre os métodos analíticos oficiais físico-químicos para controle de leite e produtos lácteos. Diário Oficial da União, Brasília, 14 de dezembro de 2006. Seção 1.

BRASIL. Ministério da Agricultura, Pecuária e Abastecimento. Instrução Normativa n. 62 de 29 de dezembro de 2011. Regulamento técnico de produção, identidade e qualidade do leite tipo A, de leite cru refrigerado, de leite pasteurizado e da coleta de leite cru refrigerado e seu transporte a granel. Diário Oficial da União, Brasília, 29 de dezembro de 2011.

BRASIL. Ministério da Agricultura, Pecuária e Abastecimento (MAPA). Bovinos e bubalinos. Disponível em: <www.agricultura.gov.br/animal/especies/bovinos-ebubalinos $>$. Acesso em: 10 out. 2015a.

BRASIL. Ministério da Agricultura, Pecuária e Abastecimento (MAPA). Projeções do agronegócio Brasil 2014/15 a 2024/2025 - projeções de longo prazo. Brasília: MAPA, 2015 b.

BORGES, L. R. et al. Milk quality according to the daily range in farm production in the Mesoregion Central Mineira and Oeste of Minas Gerais regions, Brazil. Arquivo Brasileiro de Medicina Veterinária e Zootecnia, Belo Horizonte, v. 65, n. 4, p. 1239-1246, 2013.

DOWNES, F. P. Compendium of methods for the microbiological examination of foods. 2 nd ed. Washington: APHA, 2001. 676p.

EVANGELISTA, J. Tecnologia de alimentos. São Paulo: Editora Atheneu, 2003. 652p.

FAGUNDES, C. M. et al. Presença de Pseudomonas spp. em função de diferentes etapas da ordenha com distintos manejos higiênicos e no leite refrigerado. Ciência Rural, Santa Maria, v. 36, n. 2, p. 568-572, 2006.

GODDEN, S. M. et al. The effect of sampling time and sample handling on the detection of $S$. aureus in milk from quarters with subclinical mastitis. Canadian Veterinary Journal, Ottawa, v. 43, n. 1, p. 38-42, 2002.

\section{INSTITUTO ADOLFO LUTZ. Normas analíticas do} Instituto Adolfo Lutz: métodos químicos e físicos para análise de alimentos. 4. ed., São Paulo: Instituto Adolfo Lutz, 2005. vol. 1. 1020p.

KREWER, C. C. et al. Etiology, antimicrobial susceptibility profile of Staphylococcus spp. and risk factors associated with bovine mastitis in the states of Bahia and Pernambuco. Pesquisa Veterinária Brasileira, Rio de Janeiro, v. 33, n. 5, p. 601-606, 2013.

LANGONI, H. Qualidade do leite: utopia sem um programa sério de monitoramento da ocorrência de mastite bovina. Pesquisa Veterinária Brasileira, Rio de Janeiro, v. 33, n. 5, p. 620-626, 2013.
LANGONI, H. et al. Aspectos microbiológicos e de qualidade do leite bovino. Pesquisa Veterinária Brasileira, Rio de Janeiro, v. 31, n. 12, p. 1059-1065, 2011.

MELCHIOR, M. B. et al. Comparative assessment of the antimicrobial susceptibility of Staphylococcus aureus isolates from bovine mastitis in biofilm versus planktonic culture. Journal of Veterinary Medicine. B, London, v. 53, n. 7, p. 326-332, 2006.

MELO, P. C. et al. NaOCl effect on fiogilm produced by $S$. aureus isolated from the milking environment and mastitis infected cows. Pesquisa Veterinária Brasileira, Rio de Janeiro, v. 34, n. 2, p. 109-113, 2014.

PYÖRÄLÄ, S.; TAPONEN, S. Coagulase-negative staphylococci - emerging mastitis pathogens. Veterinary Microbiology, Amsterdam, v. 134, n. 1-2, p. 1-2, 2009.

RAMALHO, A. C. et al. Eficácia in vitro de desinfetantes comerciais utilizados no pré e pós-dipping frente a $S$. aureus spp. Isolados em rebanhos leiteiros. Pesquisa Veterinária Brasileira, Rio de Janeiro, v. 32, n. 12, p. 1285-1288, 2012.

RIEKERINK, R. G. O. et al. Incidence rate of clinical mastitis on Canadian dairy farms. Journal of Dairy Science, Amsterdam, v. 91, n. 4, p. 1366- 1377, 2008.

WINCK, C. A.; THALER NETO, A. Perfil de propriedades leiteiras de Santa Catarina em relação à Instrução Normativa 51. Revista Brasileira de Saúde e Produção Animal, Salvador, v. 13, n. 2, p. 296-305, 2012.

Recebido em: 24.08.2016 Aceito em: 26.12.2016 